\title{
Microstructural Evolution during Partial Remelting of a 2024 Aluminum Alloy Prepared by Cold Pressing Ball-Milled Alloy Powders
}

\author{
$\mathrm{Pu}$ Bo Li ${ }^{1}$, Ti Jun Chen ${ }^{1, *}$, Ying $\mathrm{Ma}^{1}$, Yuan $\mathrm{Hao}^{1}$ and Ren Guo Guan ${ }^{2}$ \\ ${ }^{1}$ State Key Laboratory of Advanced Processing and Recycling of Nonferrous Metals, Lanzhou University of Technology, \\ Lanzhou 730050, China \\ ${ }^{2}$ School of Materials and Metallurgy, Northeastern University, Shenyang 110004, China
}

\begin{abstract}
A novel method, known as powder thixoforming is proposed. The effect of ball milling on the microstructural evolution of a 2024 alloy, prepared by cold pressing ball-milled powders is examined during partial remelting. Additionally the effect of reheating temperature on the microstructure has also been investigated. Results indicate that welding and deformation of the milled powders occurred. A semisolid microstructure with fine spheroidal primary particles results following partial remelting. Microstructural evolution comprises three stages, the rapid coarsening and formation of compact particles, separation of the welded particles with reduction of the particle size, and finally coarsening. Compared with the microstructural evolution of the powder compacts prepared by un-milled powders, the first stage is accelerated, but the second stage is retarded. The microstructural evolution is also accompanied by densification. A suitably elevated temperature is favorable to achieve a compact semisolid microstructure for thixoforming. [doi:10.2320/matertrans.M2015367]
\end{abstract}

(Received September 28, 2015; Accepted November 4, 2015; Published December 18, 2015)

Keywords: powder thixoforming, ball milling, semisolid microstructure, welded powders, densification

\section{Introduction}

$\mathrm{SiC}_{\mathrm{p}}$-reinforced aluminum matrix composites $\left(\mathrm{SiC}_{\mathrm{p}} / \mathrm{Al}\right)$ have been widely developed for aerospace, military, and automotive fields because of their attractive properties, such as their superior wear resistance, high temperature strength, and light weight. ${ }^{1)}$ The current fabrication techniques include pressureless infiltration and powder metallurgy (PM). ${ }^{2)} \mathrm{PM}$ process can produce $\mathrm{SiC}_{\mathrm{p}} / \mathrm{Al}$ composites, with a large range of reinforcement constituents, without the segregation of the $\mathrm{SiC}_{\mathrm{p}}$. ${ }^{3)}$ In particular, PM allows the production of components that can not be obtained by alternative methods. ${ }^{4)}$ However, the resulting components always have a very high cost because of the complex processing methods involved in $\mathrm{PM}$, and owing to the difficulty in eliminating pores, the relative density of their microstructures is relatively low. More importantly, it is difficult to fabricate the components with complex shapes and large sizes using this method, which limits its applications.

Thixoforming markedly decreases or even eliminates pores, including porosities and gas pores, and is also highly suitable for the production of large components with complex shapes. ${ }^{5)}$ The components produced by thixoforming possess superior mechanical properties because they have a lower level of porosity than those produced by fully liquid casting processes. The key aim of this technology is the fabrication of non-dendritic semisolid ingots with fine spheroidal primary particles uniformly suspended in a liquid phase. The powder compacts, prepared by the cold pressing of atomized powders, can be used as a feedstock for thixoforming. ${ }^{6)}$ Thus, combining the advantages of both PM and thixoforming, a new approach called powder thixoforming, has been proposed for the preparation and formation of particle-reinforced composites. The blending and cold pressing steps involved in PM are applied to fabricate initial ingots with a uniform distribution of

*Corresponding author, E-mail: chentj1971@126.com reinforcements. Subsequently, the ingots are subjected to partial remelting and thixoforming.

Pseudo-semisolid thixoforming and semisolid powder processing are currently the most similar techniques to powder thixoforming. The pseudo-semisolid thixoforming is intended to produce functional composites with a high volume of reinforcements. ${ }^{7)}$ Its semisolid state exists as a pseudo-semisolid state, the solid phase consists of reinforcements constituents (such as $\mathrm{Al}_{2} \mathrm{O}_{3}$ particles), and the entire alloy matrix (such as the $\mathrm{Al}$ alloy) exists in a liquid state. To meet the liquid fraction requirement for thixoforming (40$60 \%$ ), the solid fraction, i.e., the reinforcement fraction, must be $40-60 \%$ or greater. Specifically, this technique is suitable for the formation of composites with a high reinforcement fraction. The semisolid powder processing can be characterized as a PM liquid sintering technique because of the low liquid fraction (less than 10\%). ${ }^{8}$ ) The formability of the resulting semisolid ingots is relatively poor due to the low liquid fraction, and thus this method is not suitable for the formation of components with a complicated shape. Therefore, the technique proposed in this paper is a new method for the formation of particlereinforced composites.

The authors' previous investigation has studied the microstructural evolution of a 2024 powder compacts prepared with non-milled alloy powders; the results indicate that semisolid ingots with small (approximately $23 \mu \mathrm{m}$ ) spheroidal primary particles, which are suitable available for thixoforming, can be obtained. ${ }^{9)}$ To prepare the particlereinforced Al matrix composites by powder thixoforming, ball milling must be employed to uniformly disperse the reinforcement materials within the matrix alloy powders. However, the effect of ball milling on the microstructural evolution is unknown. Therefore, the microstructural evolution of 2024 powder compacts, prepared by cold pressing ball-milled alloy powders, was initially studied during partial remelting to further illustrate that of $\mathrm{SiC}_{\mathrm{p}} / 2024$ Al-based composite. 


\section{Experimental Procedure}

A commercially-available gas-atomized 2024 Al alloy powder $\left(\mathrm{Al}_{\mathrm{p}}\right)$ with an average particle size of $20 \mu \mathrm{m}$ was used as the raw material for the powder compacts. The composition of the material is $\mathrm{Al}-4.22 \mathrm{Cu}-1.35 \mathrm{Mg}-0.5 \mathrm{Si}-$ $0.5 \mathrm{Fe}$ (in mass \%). To determine the appropriate reheating temperature, the $\mathrm{Al}_{\mathrm{p}}$ was analyzed by a differential thermal analyzer (DTA) and the solidification range was determined to be between $771-937 \mathrm{~K}$.

The ball milling was performed using a planetary ball milling machine. For each procedure, we loaded $45 \mathrm{~g}$ of the $\mathrm{Al}_{\mathrm{p}}$. The ball to powder weight ratio, rotation speed, and milling period were $5: 1,100 \mathrm{r} / \mathrm{min}$ and $30 \mathrm{~min}$, respectively. Under these conditions, the $\mathrm{SiC}_{\mathrm{p}}$ could be homogeneously distributed in the Al matrix powders. ${ }^{10)}$ Subsequently, $10 \mathrm{~g}$ of the ball-milled or non-milled $\mathrm{Al}_{\mathrm{p}}$ was uniaxially coldcompacted under a pressure of $300 \mathrm{MPa}$ for $5 \mathrm{~min}$ to form a green compact of $30 \mathrm{~mm}$ in diameter and $7 \mathrm{~mm}$ in height. By repeating the cold-pressing procedure, a number of green compacts were produced, which were used as the initial billets for partial remelting. Subsequently, some of the billets were heated at a semisolid temperature of $908 \mathrm{~K}$ for various durations $(0-60 \mathrm{~min})$ to investigate the microstructural evolution of the powder compacts during partial remelting. The other billets were heated at various temperatures, namely, $898,903,913$, and $918 \mathrm{~K}$ for $30 \mathrm{~min}$ to study the effects of the reheating temperature on the semisolid microstructure. All of the heated specimens were quickly quenched in a Bibased alloy melt at a temperature of $318 \mathrm{~K}$.

The metallographic specimens were cut along the radial direction of the quenched specimens. Subsequently, the cross section of a selected specimen was finished and polished using standard metallographic techniques, and observed with a QUANTA FEG450 scanning electron microscope (SEM) to study the pore evolution of the powder compacts during partial remelting. Subsequently, the specimens were etched using Keller's etchant and a SEM and/or optical microscope $(\mathrm{OM})$ were used to study the microstructural evolution during partial remelting. To quantitatively examine the primary particle size, liquid fraction, as well as the size and percentage of the pores, the associated SEM and OM images were analyzed using Image-Pro Plus software. Three typical images with a magnification of $500 \times$ were examined.

\section{Results and Discussion}

\subsection{Microstructure of the green compacts}

To clarify the microstructural evolution of the powder compacts during partial remelting, the microstructure of the green compacts should be initially examined. The microstructure of the green compacts prepared by the non-milled powder consists of spheroidal powders (Fig. 1(a)). The microstructure of the single powder consists of fine $\alpha$-Al grains and intergranular eutectics (marked by the arrows in Fig. 1(a)), resulting from the rapid cooling during the atomization preparation process. However, welded and deformed powders (marked by the arrows in Fig. 1(b)) were observed for the green compacts that was consolidated from the milled powders, and there was a reduction in the eutectic

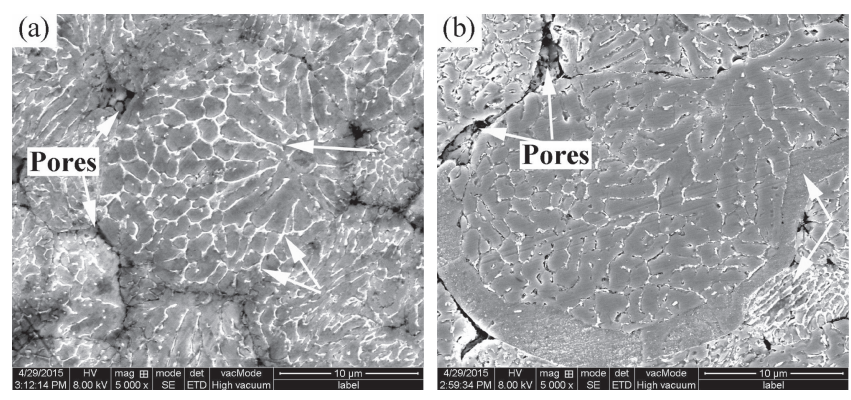

Fig. 1 Micrographs of the powder compacts prepared by (a) non-milled and (b) ball-milled powders.

amount of the powders (comparing Figs. 1(a) and (b)). Furthermore, there was an increase in the size of the milled powders. Therefore, it can be determined that ball milling has a significant effect on the microstructure of the powder compacts. In addition, it can be observed that many pores exist between the powders (marked by the arrows in Fig. 1) of both the ball-milled and non-ball-milled products.

Figure 2 shows the morphologies of the non-milled and milled powders. It shows that the non-milled powders are spherical in shape (Fig. 2(a)). However, the milled powders are welded together and have a large size, irregular morphology, and rough surfaces (Figs. 2(b) and (c)). The size and morphology of the powders are primarily governed by mechanisms such as the welding, fracturing, and deformation of powders during the ball milling process. ${ }^{11)}$ Owing to the deformation, the morphology of the powder changes from a spheroidal shape to an irregular shape. The deformed powders also weld together to form large powder particles. Moreover, ball-powder collision and ball-ball sliding can increase the powder temperature, which results in dissolution of the eutectics towards the primary $\alpha$-Al phase, and consequently decreases the eutectic amount. The ball-milled powders possess high-density dislocations, which result from the plastic deformation during the ball milling. ${ }^{3)}$ These dislocations provide convenient channels for further dissolution of the eutectic phases. The powders are merely mechanically consolidated during cold pressing, and thus, it is difficult to eliminate pores from the green compacts (Fig. 1). Therefore, the pore evolution during partial remelting should be examined.

\subsection{Microstructural evolution of the powder compacts during partial remelting}

Figure 3 shows the microstructures of the powder compacts heated at $908 \mathrm{~K}$ for various durations. On heating for $2 \mathrm{~min}$, it is apparent that there is a reduction in the eutectic phases (comparing Figs. 1(b) and 3(a)). The powders transform into compact particles without grain boundaries. In addition, some white particles and black holes can be observed (marked by A and B in Fig. 3(a), respectively). The XRD results show that the eutectics of 2024 alloy only consist of $\alpha-\mathrm{Al}$ and $\theta-\mathrm{CuAl}_{2}$ phase (Fig. 4), which is contradictory to the previous investigation. ${ }^{12)}$ This should be attributed to the reason that the content of the $\mathrm{Al}_{2} \mathrm{CuMg}$ phase is very low, and thus the $\alpha-\mathrm{Al}$ and $\theta$ phase are regarded as the main eutectic phases in this alloy. During heating, the 

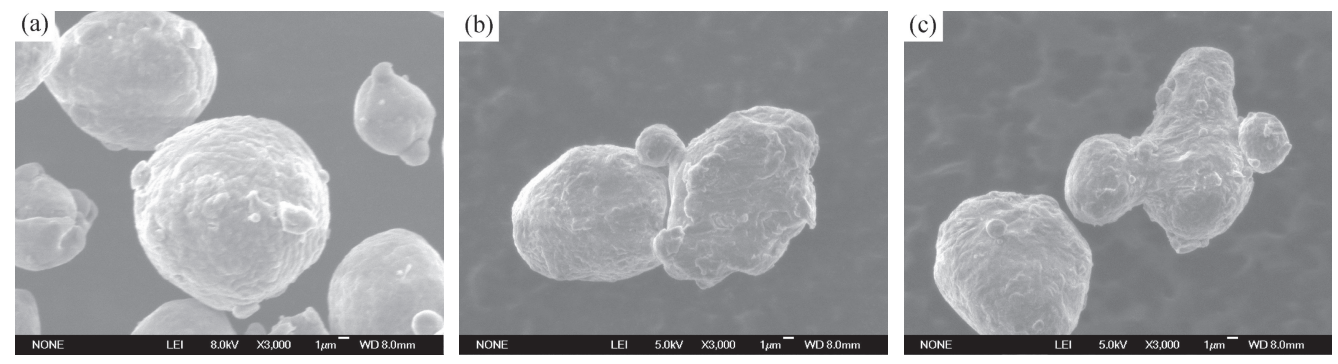

Fig. 2 Morphologies of (a) non-milled powders, (b) and (c) ball-milled powders of 2024 alloy.
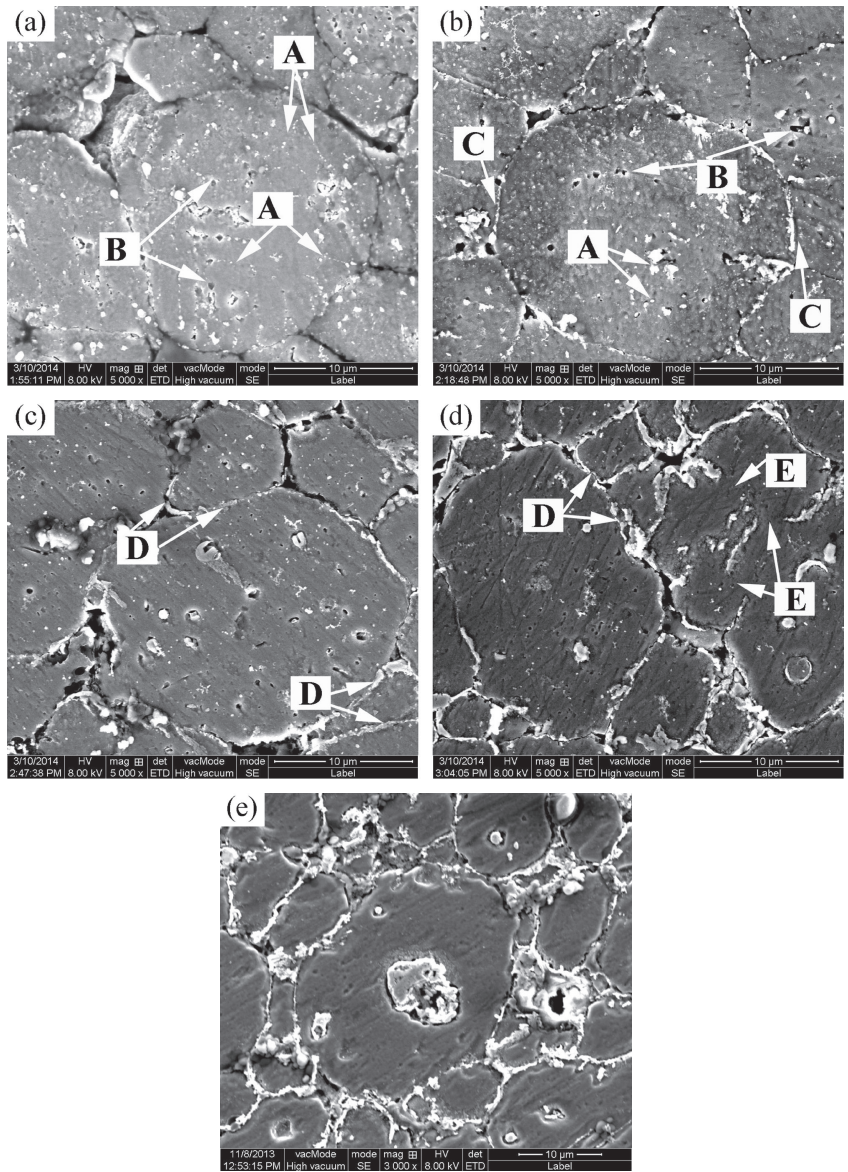

Fig. 3 Micrographs of the powder compacts heated at $908 \mathrm{~K}$ for various periods and subsequently quenched. Heating times of (a) $2 \mathrm{~min}$, (b) $3 \mathrm{~min}$, (c) $5 \mathrm{~min}$, (d) $10 \mathrm{~min}$, and (e) $30 \mathrm{~min}$.

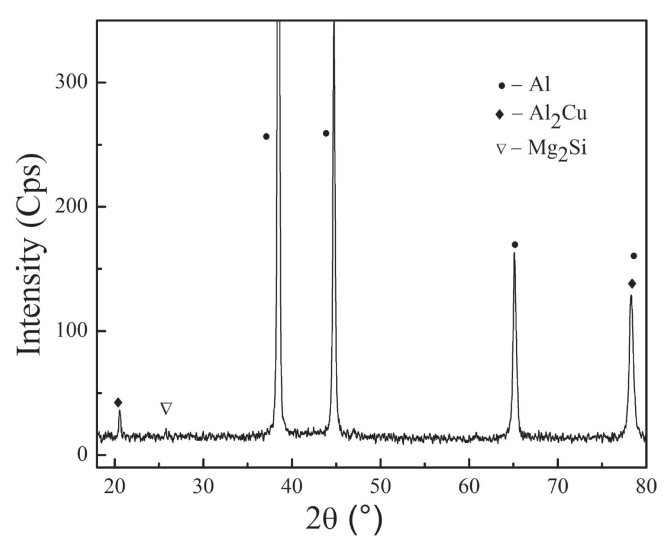

Fig. 4 XRD spectrum of the 2024 aluminum alloy. eutectic phases dissolve towards the surrounding $\alpha$-Al phase, ${ }^{13)}$ resulting in a decrease in the eutectic amount. From the perspective of phase transformation, this process can be expressed by the reaction, $\theta \rightarrow \alpha$. Most of the intergranular eutectics can dissolve and even all of them completely disappear in some local zones. The disappearance of the eutectics causes the grains to coalesce within the powders. The powders then form into compact particles because of this coalescence (Fig. 3(a)). However, the microstructure of the powder compacts prepared by the non-milled powder does not transform into compact particles until the specimen is heated for a period of $3 \mathrm{~min} .{ }^{9}{ }^{9}$ This could be attributed to two reasons. The first is that the amount of eutectics within the ball-milled powders is generally lower than that within the non-milled powders. The second is that the high-density dislocations within the milled powders are beneficial for the rapid dissolution of the eutectic phases. Consequently, the coarsening rate for the fine grains within the milled powders is accelerated. However, some eutectics cannot be dissolved when the temperature of the specimen reaches the eutectic point; they subsequently melt, forming liquid pools. Considering the phase transformation, this process can be expressed by the reverse eutectic reaction, $\theta+\alpha \rightarrow \mathrm{L}$. The white particles (marked by A in Fig. 3(a)) should consist of the solidified liquid phase. Moreover, the black holes within the powders should also consist of the liquid phase, which was etched during the preparation of the metallographic samples (marked by B in Fig. 3(a)). Therefore, the primary behaviors during the first $0-2 \mathrm{~min}$ of heating involve the rapid coarsening of the fine grains within the powders and the formation of compact particles due to the dissolution of the eutectics.

When the heating period exceeds 2 min, the liquid phase around the particles starts to develop (marked by $\mathrm{C}$ in Fig. 3(b)). Owing to the increase in temperature, the liquid phase gradually increases during the subsequent heating, accompanied by the separation of the welded particles (marked by D in Figs. 3(c) and (d)). The welded powders generally store a large amount of energy following ball milling. ${ }^{3)}$ In particular, the energy of the welded interfaces should be greater than that of the particles because of the differences in their crystal orientation. Thus, these welded sites may partially melt or be penetrated by the liquid phase during partial remelting, resulting in the separation of the welded particles. As shown by Fig. 3(d), there is contact between the welded particles and their neighboring particles at the sites denoted by ' $E$ ', and the liquid phase will penetrate along these welded sites, or these sites will directly melt. The 

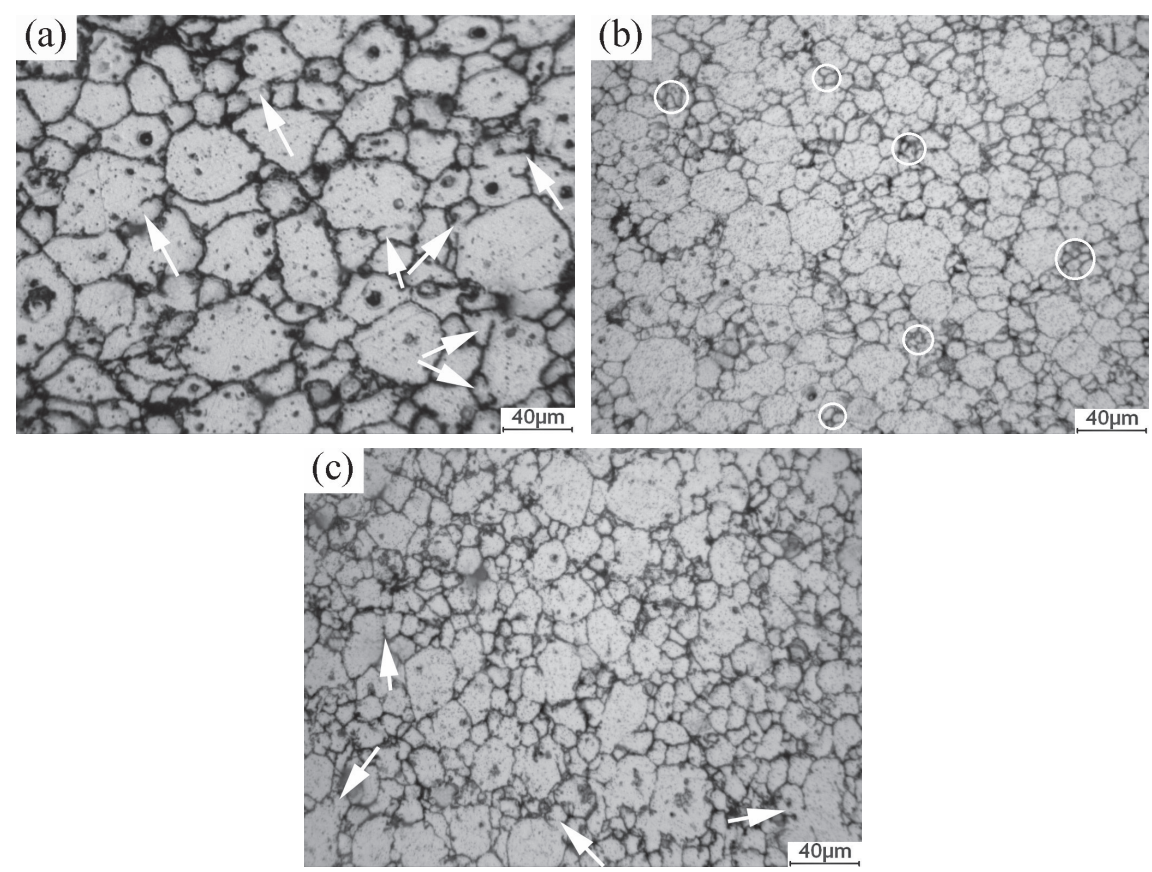

Fig. 5 Micrographs of the powder compacts heated at $908 \mathrm{~K}$ for various durations and subsequently quenched. Heating times of (a) $10 \mathrm{~min}$, (b) $30 \mathrm{~min}$, and (c) $60 \mathrm{~min}$.

separation process can be expressed by the reaction of, $\alpha \rightarrow \mathrm{L}$. As the heating period is further extended, the microstructure develops into individual polygonal particles that are separated by the liquid phase (Fig. 3(e)). Namely, the separation of the welded particles is complete following a heating period of $30 \mathrm{~min}$. In addition, the size of the liquid pools increases and the number of liquid pools decreases during partial remelting (by comparing Figs. 3(a) and (b)). The solid/liquid interfacial energy decreases as the liquid pools (marked by A and B in Fig. 3(b)) within the particles coarsen. Moreover, the formed liquid phase is rich in solutes (such as $\mathrm{Cu}$ ), and some of the $\mathrm{Cu}$ will dissolve towards the $\alpha$ Al phase. Therefore, the primary behavior that occurs over the heating period of 2-30 min involves the separation of the welded particles.

Figure 5 presents the microstructures of the powder compacts that was heated at $908 \mathrm{~K}$ for more than $10 \mathrm{~min}$. All the microstructures consist of particles with significantly different sizes, and interparticle eutectics (Fig. 5). With regard to semisolid microstructures obtained from the partial remelting of casting ingots, the structures that solidified from the liquid phase during quenching are significantly smaller than the primary particles due to the rapid solidification rate of the liquid phase. ${ }^{14)}$ Therefore, there is a clear distinction between the solid phase and liquid phase. However, there are no obvious differences between the images of the semisolid microstructures in this study. This could be because of the low eutectic amount owed to the low solute content of the alloy, and the small size of the particles (approximately $24 \mu \mathrm{m})$ that originate from the powders. Figure 6 presents the microstructure of a billet that was heated at $983 \mathrm{~K}$ (i.e., the billet completely transformed into a liquid phase before quenching) and subsequently quenched. The particles are similar to the small particles shown in Fig. 5, which implies that the small particles shown in Fig. 5 indeed originate from

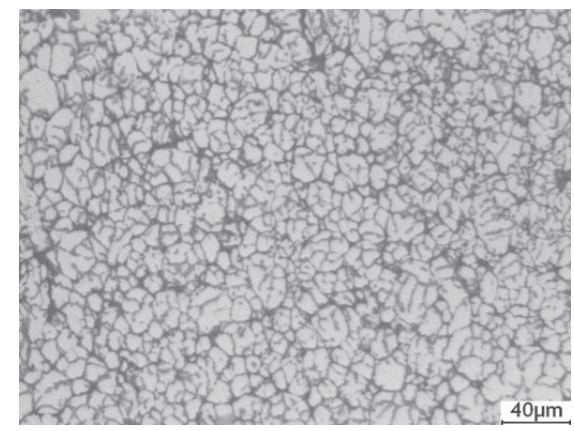

Fig. 6 Micrograph of the powder compacts heated at $983 \mathrm{~K}$ for $30 \mathrm{~min}$ and subsequently quenched.

the solidification of the liquid phase. The larger particles in Fig. 6 have a size of approximately $5 \mu \mathrm{m}$. Thus the particles that are smaller than $5 \mu \mathrm{m}$ (marked by circles in Fig. 5(b)) are the solidified liquid phase.

The above discussion indicates that the separation of the large welded particles was not complete following a heating period of $10 \mathrm{~min}$ (Fig. 3(d)); this can be clearly observed in Fig. 5(a) (marked by arrows in Fig. 5(a)). As the heating period is extended, the primary particle size decreases and the liquid fraction increases (by comparing Figs. 5(a) and (b)). These variations can be clearly observed from the graph in Fig. 7. Figure 8 shows the microstructures of the powder compacts prepared by the non-milled powder that was heated at $908 \mathrm{~K}$ for various periods. It can be observed that the primary particles are small (by comparing Figs. 5(a) and $8(\mathrm{a})$ ). As the heating period is further extended to $30 \mathrm{~min}$ (i.e., the separation of the welded particles is already completed for the powder compacts prepared by the milled powders), the microstructure becomes similar to that of the powder compacts prepared by the milled powder (comparing 


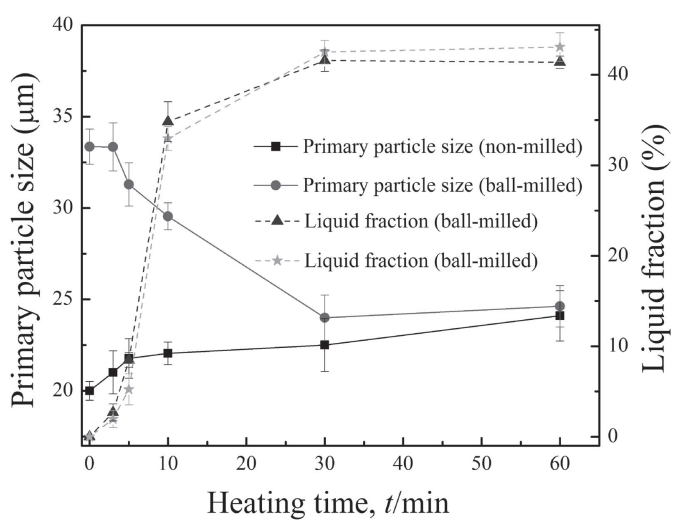

Fig. 7 Variation in the primary particle size and liquid fraction with heating duration.

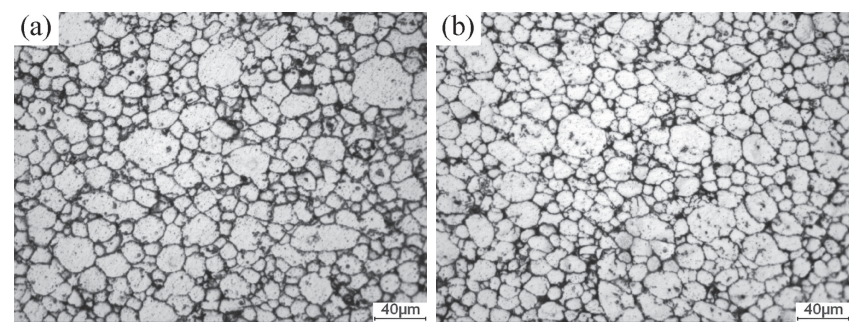

Fig. 8 Micrographs of the powder compacts prepared by the non-milled powder that was heated at $908 \mathrm{~K}$ for various periods and subsequently quenched. Heating times of (a) $10 \mathrm{~min}$ and (b) $30 \mathrm{~min}$.

Figs. 5(b) and 8(b)). The microstructural differences between the powder compacts prepared by the ball-milled and nonball-milled powders gradually decrease as the heating period is extended. Thus, the reduced particle size of the powder compacts prepared by the milled powder could be attributed to the separation of the welded particles. However, the rate of microstructural evolution decreases because of the formation of the welded powders. Therefore, the separation of the welded particles is also accompanied by a decrease in the size of the primary particles.

There is very little microstructural change over the heating period of 30-60 min (comparing Figs. 5(b) and (c)); however, the quantitative examinations show that there is a slight increase in the size of the primary particles over this period (Fig. 7). Following a heating period of $30 \mathrm{~min}$, the coarsening mechanism could be due to Ostwald ripening because there would be a sharp increase in the particle size if coalescence occurred. It is likely that alumina on the surfaces of the powders can hinder the coarsening. But the breakage of the oxide film in certain localized zones potentially generates during reheating because of the large difference in the coefficient of thermal expansion between the Al matrix and oxide layer. ${ }^{15)}$ Thus, new connections between the primary particles in some localized zones can develop (marked by the arrows in Fig. 5(c)). However, the coarsening rate of the primary particles is lower than that of the casting ingots during partial remelting. ${ }^{16)}$ Consequently, although the coarsening rate in some local sites may be facilitated due to formation of these fresh contact zones, Ostwald ripening is greatly hindered, resulting in the low coarsening rate. In addition, following heating for $30 \mathrm{~min}$, the liquid fraction
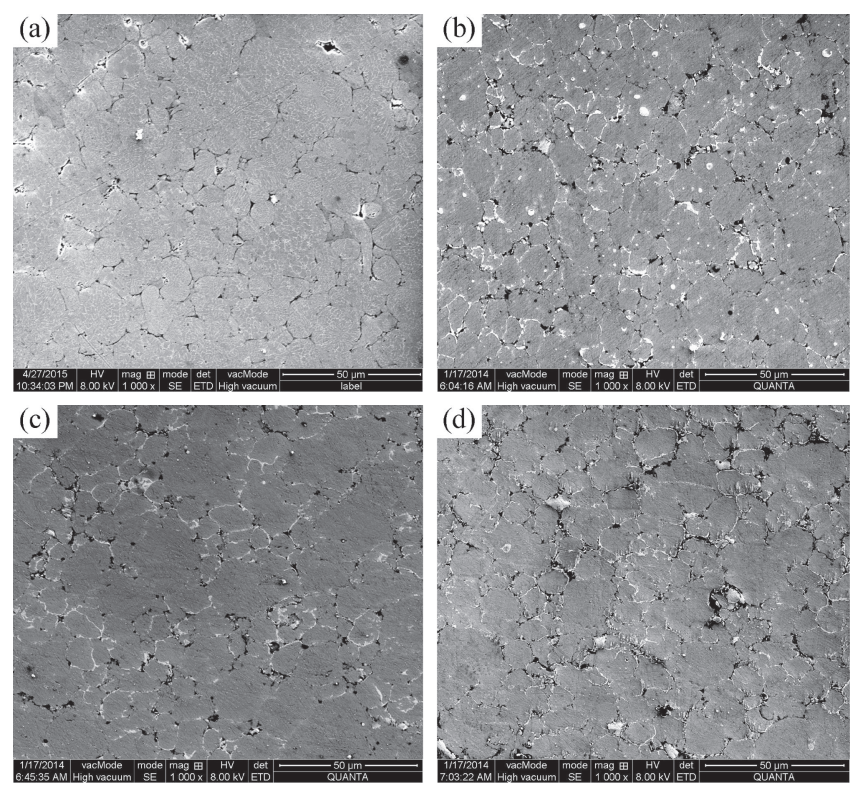

Fig. 9 Micrographs obtained from the unetched samples that were heated at $908 \mathrm{~K}$ for various durations and subsequently quenched. Heating times of (a) $0 \mathrm{~min}$, (b) $10 \mathrm{~min}$, (c) $30 \mathrm{~min}$, and (d) $60 \mathrm{~min}$.

remains relatively constant (comparing Figs. 5(b) and (c)), which implies that the final solid/liquid equilibrium state during this period has been attained. Therefore, slight coarsening occurs when the semi-solid systems reach a solid/liquid equilibrium state.

Pores are responsible for the microstructural development, strength, and other properties. ${ }^{17)}$ Thus it is necessary to analyze the pore evolution in detail. Figure 9 shows the presence of many intergranular pores within the microstructure (Fig. 9(a)). As the heating time is extended, the pore size gradually decreases, accompanied by a decrease in the number of pores (Figs. 9(b)-(d)). These differences are clearly demonstrated by the results of the quantitative examination, as shown in Table 1. The level of pores decreases from 3.646 to $1.495 \%$ when the heating period is extended from 0 to $60 \mathrm{~min}$. The percentage of pores $(1.495 \%)$ is similar to that of the alloy, where the components were prepared by semisolid powder processing. ${ }^{18)}$

During the sintering of Al alloys, an important densification mechanism is that pores are filled by the liquid phase. ${ }^{19)}$ As the heating proceeds, the amount of liquid surrounding the primary particles increases, resulting in an obvious densification of the material (comparing Figs. 9(a) and (b)). By considering that an equilibrium exists between the gas pressure within the pores, the external gas pressure, and the pressure exerted by the liquid surface tension, the effective driving stress for densification, $P_{\mathrm{s}}$, was predicted by the following equation: ${ }^{17)}$

$$
P_{\mathrm{s}}=P_{\mathrm{v}}-2 \gamma / r
$$

Where, $P_{\mathrm{v}}$ is the pressure within the pore, $r$ is the pore radius, $\gamma$ is the surface tension of the liquid, and $2 \gamma / r$ is the pressure resulting from the gas-liquid interfacial energy. The present experiment was conducted under an air atmosphere, and thus the gases within the pores mostly consist of nitrogen and oxygen. The nitrogen within the pores can react with the Al 
Table 1 Variation in the pore diameter and percentage with heating time.

\begin{tabular}{ccccc}
\hline Heating time $(\mathrm{min})$ & 0 & 10 & 30 & 60 \\
\hline Pore diameter $(\mu \mathrm{m})$ & 2.526 & 2.228 & 2.107 & 2.073 \\
Pore percentage $(\%)$ & 3.646 & 2.436 & 1.652 & 1.495 \\
\hline
\end{tabular}
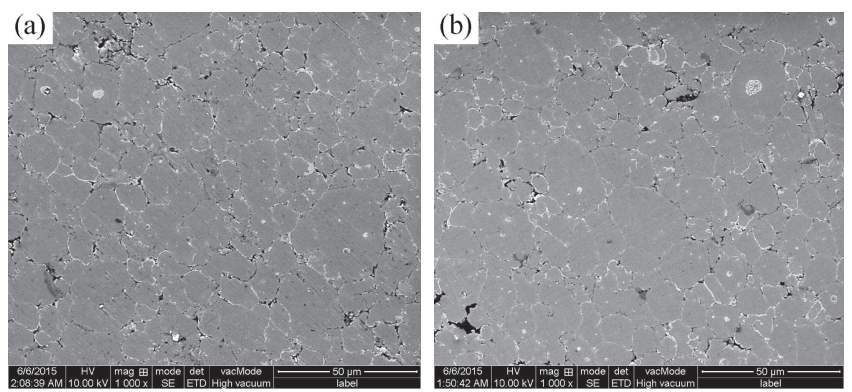

Fig. 10 Micrographs obtained from the unetched samples prepared by the non-milled powder that were heated at $908 \mathrm{~K}$ for various periods and subsequently quenched. Heating times of (a) $10 \mathrm{~min}$ and (b) $60 \mathrm{~min}$.

matrix to form AlN, which consumes the nitrogen gas and thus decreases the $P_{\mathrm{v}}{ }^{20)}$ Moreover, the oxygen within the pores can react with the alloy matrix alloy, which also further decreases the $P_{\mathrm{v}}$. Specifically, as the reheating period is extended, the pore-filling ability increases because of the increased liquid fraction and the decreased pressure within the pores (Figs. 9(a)-(c)). In addition, the reduction in the pore size during the partial remelting also contributes to the increased $P_{\mathrm{s}}$. The pore size and percentage remain relatively unchanged when the reheating period is extended from 30 to $60 \mathrm{~min}$ (Fig. 9(d)). This could be because the pressure within the pores is close to the final equilibrium state following a heating period of $30 \mathrm{~min}$. Figure 10 indicates that the microstructures of the powder compacts prepared by the nonmilled powder also possess many pores. However, there is very little difference in the pore variation of the powder compacts prepared by the ball-milled and non-ball-milled powders (comparing Figs. 9(b) and 10(a) or 9(d) and 10(b)). Specifically, the effect of the ball milling on the pore evolution is very small. Therefore, during partial remelting, the microstructural evolution is also accompanied by densification.

Consequently, ball milling has a large effect on the microstructure. Following milling, large irregular powder particles can form and the eutectic amount decreases. The microstructural evolution can be divided into three stages, namely, the initial rapid coarsening and formation of compact particles owing to the dissolution of the eutectics ( $0-2 \mathrm{~min})$, the separation of the welded particles and a reduction in the particle size because of the partial remelting of the compact particles (2-30 $\mathrm{min})$, and the slight coarsening of the primary particles resulting from the hindered Ostwald ripening (30$60 \mathrm{~min}$ ). Compared with the microstructural evolution of the powder compacts consisting of non-milled powders, the first stage is accelerated, but the second stage is retarded. The effect of ball milling on the pore evolution of the powder compacts is very small. The number of pores decrease as the heating period is extended, and a relatively compact semi-
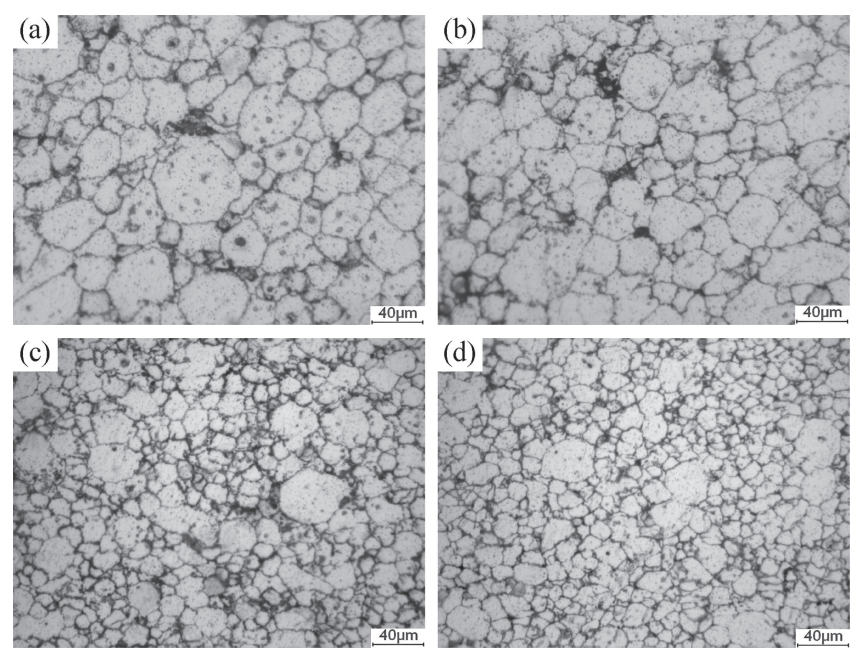

Fig. 11 Micrographs of the powder compacts heated for $30 \mathrm{~min}$ at (a) $898 \mathrm{~K}$, (b) $903 \mathrm{~K}$, (c) $913 \mathrm{~K}$, and (d) $918 \mathrm{~K}$.

solid microstructure with small and spheroidal primary particles can be obtained.

\subsection{Effect of reheating temperature on semisolid micro- structure}

Figure 11 presents the microstructures of the powder compacts that was heated for $30 \mathrm{~min}$ at various temperatures. Together with Fig. 5(b), it is easy to be observed that the particle size decreases and the amount of liquid increases as the reheating temperature rises, which is clearly shown in Fig. 12.

At low temperatures, the partially remelted portion of the primary particles is relatively small, resulting in a low liquid fraction and a short distance between the particles. In particular, the welded particles, which are large in size and irregular in morphology, are numerous. Thus, the microstructure is characterized by large irregular particles that are connected to each other (Fig. 11(a)). As the temperature rises, more sections of the particles will melt, resulting in a decreased particle size and increased liquid phase (Figs. 11(b) and 5(b)). When the temperature further increases, the particle size further decreases and the amount of liquid further increases (comparing Figs. 11(c) and (d)). Furthermore, owing to the influence of the surface curvature, the edges and corners of the particles with a large curvature will preferentially melt. In addition, the separation of the welded particles will be complete when the temperature exceeds $908 \mathrm{~K}$. These two factors do not only decrease the particle size, but also result in the development of relatively spheroidal primary particles. The microstructural evolution of the powder compacts prepared by the non-milled powder is similar to that of the alloy prepared by the ball-milled powder, i.e., the primary particle size decreases and the liquid fraction increases as the reheating temperature increases (Figs. 13(a) and (b)). However, the primary particles of the powder compacts prepared by the milled powders are significantly larger and more regular than those of the alloy prepared by the un-milled powders (comparing Figs. 11(a) and 13(a)). The microstructural differences gradually decrease or even disappear when the temperature exceeds 


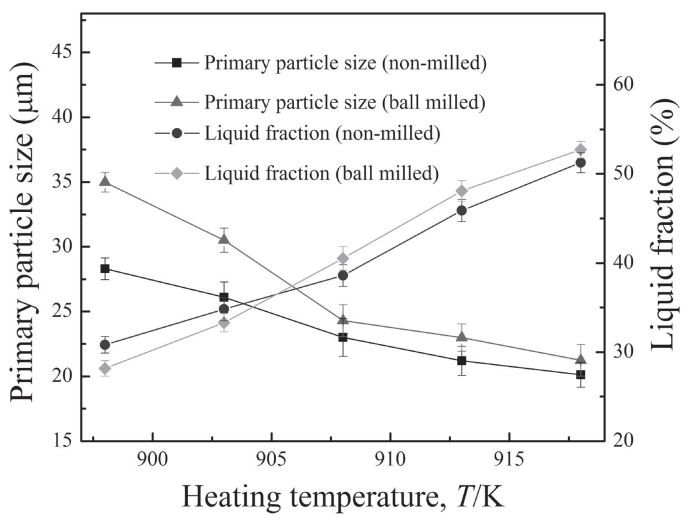

Fig. 12 Variation in the primary particle size and liquid fraction with the heating temperature.

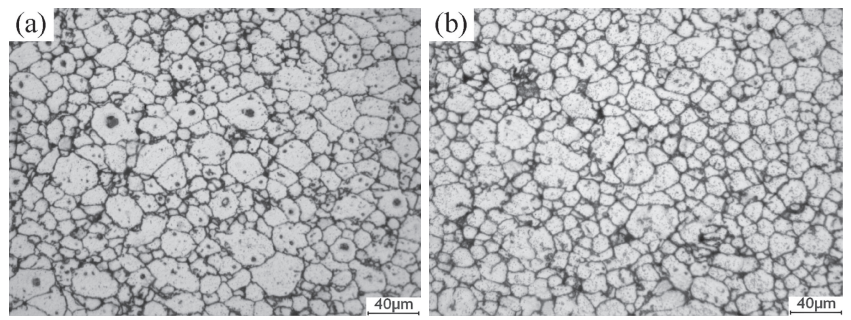

Fig. 13 Micrographs of the powder compacts prepared by the non-milled powder that was heated for $30 \mathrm{~min}$ at (a) $898 \mathrm{~K}$ and (b) $913 \mathrm{~K}$.
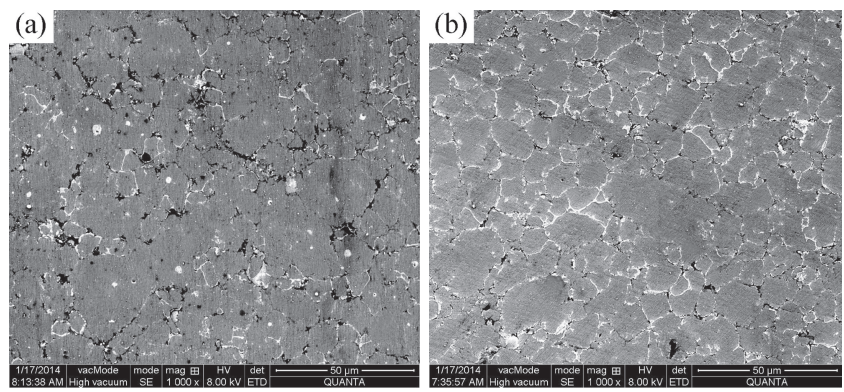

Fig. 14 Micrographs obtained from the unetched samples that were heated for $30 \mathrm{~min}$ at (a) $898 \mathrm{~K}$ and (b) $918 \mathrm{~K}$.

$908 \mathrm{~K}$; this is because the separation of the large and irregular-shaped welded particles will proceed as the reheating temperature increases.

Figure 14 shows the microstructures obtained from the unetched samples that were heated for $30 \mathrm{~min}$ at various temperatures. Together with Fig. 9(c), it can be found that the change in the pore variation with reheating temperature is similar to that with the reheating time, i.e., the amount and size of the pores decrease as the reheating temperature rises, which is clearly indicated by the results of the quantitative examinations shown in Table 2 . Under a reheating temperature of $898 \mathrm{~K}$, the liquid phase in the semisolid microstructure is at its lowest level. Thus, the pore-filling ability is relatively weak, resulting in a high pore percentage of $2.920 \%$ (Fig. 14(a)). The liquid fraction apparently increases as the temperature rises (Fig. 12). Simultaneously, the increase in temperature also accelerates the AIN and oxide formation. Thus, the pore-filling ability increases as the reheating temperature increases (comparing Figs. 14(a) and
Table 2 Variation in the pore diameter and percentage with reheating temperature.

\begin{tabular}{cccccc}
\hline Heating temperature $(\mathrm{K})$ & 898 & 903 & 908 & 913 & 918 \\
\hline Pore diameter $(\mu \mathrm{m})$ & 2.229 & 2.164 & 2.107 & 1.430 & 0.866 \\
Pore percentage $(\%)$ & 2.920 & 2.045 & 1.652 & 1.301 & 1.092 \\
\hline
\end{tabular}

(b)). Although the behaviors that occurred during the densification are similar to those that occurred as the reheating time was extended, the effect of the reheating temperature on the densification is greater than that of the reheating time (comparing Tables 1 and 2). Therefore, the densification is enhanced as the reheating temperature is increased.

Consequently, it can be concluded that an increased reheating temperature supports the development of a compact semisolid microstructure with small and spheroidal primary particles. However, it also generates a large amount of liquid phase, and thus some of the advantages of thixoforming can be lost.

\section{Conclusion}

(1) A semisolid ingot with fine spheroidal primary particles, which is available for thixoforming, can be obtained following the partial remelting. Thus powder thixoforming is believed to be a highly feasible technology to carry out net-shape forming of particlereinforced metal matrix composites.

(2) Compared with the non-milled powders, large irregular powder particles can form due to the plastic deformation and welding of the powder that occurs during the ball milling process. The eutectic amount also decreases because the ball milling facilitates the dissolution of the eutectic phases towards the primary $\alpha$-Al phase.

(3) The microstructural evolution of the powder compacts can be divided into three stages, namely, the initial rapid coarsening and the formation of compact particles, the separation of the welded particles and reduction of the particle size, and the slight coarsening.

(4) Compared with the microstructural evolution of the powder compacts composed of non-milled powders, the first stage is accelerated because of a reduction of the eutectics in the milled powders and the rapid dissolution of the eutectics due to the high-density dislocations; however, the second stage is retarded because of the formation of the welded powders.

(5) As the reheating period is extended, the pore-filling ability is enhanced because of the increase of the liquid fraction and the reduction of the pressure within the pores. Thus, the pore percentage decreases from 3.646 to $1.495 \%$ when the reheating time is extended from 0 to $60 \mathrm{~min}$. The effect of ball milling on the pore evolution is small because there is very little difference in the pore variations of the powder compacts prepared by the ball-milled and non-ball-milled powders.

(6) The reheating temperature also has an obvious effect on the microstructure of the powder compacts. The 
behaviors that occurred during the densification are similar to those that occurred as the reheating time was extended. However, the effects of the reheating temperature on the densification are greater than those of the reheating time.

(7) An suitably increased reheating temperature is beneficial for the development of a compact semisolid microstructure with small and spheroidal primary particles.

\section{Acknowledgments}

The authors wish to express thanks to financial support from the Basci Scientific Fund of Gansu University (Grant No. G2014-07), the Program for New Century Excellent Talents in the University of China (Grant No. NCET-100023) and the Program for Hongliu Outstanding Youngth of Lanzhou University Of Technology.

\section{REFERENCES}

1) M. L. Ted Guo and C.-Y. A. Tsao: Compos. Sci. Technol. 60 (2000) 65-74.

2) N. P. Cheng, S. M. Zeng and Z. Y. Liu: J. Mater. Process. Technol. 202 (2008) 27-40.

3) J. B. Fogagnolo, F. Velasco, M. H. Robert and J. M. Torralba: Mater Sci. Eng. A 342 (2003) 131-143.
4) J. M. Torralba, C. E. Da Costa and F. Velasco: J. Mater. Process. Technol. 133 (2003) 203-206.

5) M. R. Rokni, A. Zarei-Hanzaki, H. R. Abedi and N. Haghdadi: Mater. Des. 36 (2012) 557-563.

6) C. E. Wen, K. Yasue and Y. Yamada: J. Mater. Sci. 36 (2001) 17411745.

7) Y. S. Cheng and S. J. Luo: Acta Metall. Sin. 23 (2010) 21-26.

8) Y. F. Wu, G.-Y. Kim, I. E. Anderson and T. A. Lograsso: Acta Mater. 58 (2010) 4398-4405.

9) P. B. Li, T. J. Chen, S. Q. Zhang and R. G. Guan: Metals 5 (2015) 547564.

10) W. Fu: Master thesis, Lanzhou University of Technology Lanzhou, China, (2013).

11) K. Morsi and A. Esawi: J. Mater. Sci. 42 (2007) 4954-4959.

12) R. D. Schueller, F. E. Wawner and A. K. Sachdev: J. Mater. Sci. 29 (1994) 424-435.

13) H. Okamoto: Desk Handbook: Phase Diagrams for Binary Alloys, (ASM International: Materials Park, Ohio, 2000) pp. 29-30.

14) T. J. Chen, G. X. Lu, Y. Ma, Y. D. Li and Y. Hao: J. Alloy. Compd. 486 (2009) 124-135.

15) Z. Y. Liu, T. B. Sercombe and G. B. Schaffer: Metall. Mater. Trans. A 38 (2007) 1351-1357.

16) H. T. Jiang and M. Q. Li: J. Mater. Eng. Perform. 13 (2004) 488-492.

17) K. M. Kareh, P. D. Lee, R. C. Atwood, T. Connolley and C. M. Gourlay: Scr. Mater. 89 (2014) 73-76.

18) Y. F. Wu and G.-Y. Kim: J. Mater. Process. Technol. 211 (2011) 13411347.

19) G. B. Schaffer, B. J. Hall, S. J. Bonner, S. H. Huo and T. B. Sercombe: Acta Mater. 54 (2006) 131-138.

20) G. B. Schaffer, J. Y. Yao, S. J. Bonner, E. Crossin, S. J. Pas and A. J. Hill: Acta Mater. 56 (2008) 2615-2624. 